[Agr. Biol. Chem., Vol. 28, No. 3, p. 179 183, 1964]

\title{
Biochemical Studies on "Bakanae" Fungus. Part 69. Synthesis of Substances related to Gibberellins
}

\section{Part XII* Reactions of Compounds derived fr $m$ Gibberellin $\mathrm{C}$}

\author{
By Kenji Mori, Masanao Matsur and Yusuke Sumikr \\ Department of Agricultural Chemistry, Faculty of Agriculture \\ The University of Tokyo, Tokyo \\ Received December 13, 1963
}

\begin{abstract}
Degradation of gibberellin C afforded methyl 1,7-dimethyl-2 $\alpha$-hydroxy-8-oxo-7 $\alpha$-gibb-4a(4b)-ene1,10-dicarboxylate, from which gibberellin $\mathrm{C}$ was reconstructed. Reactions of desoxogibberellin $\mathrm{C}$ are also described.
\end{abstract}

It has been shown that gibb-4a (4b) -ene1,10-dicarboxylates smoothly relactonize to afford gibbane $1 \rightarrow$ ta-lactonic acids ${ }^{1}$. This paper describes further examples of relactonization as well as several new compounds derived from gibberellin $\mathrm{C}$.

2(eq)-Hydroxy-epimer of Gibberellin $\mathrm{C}^{2)}$ (Isogibberellin $\left.\mathbf{A}_{1}{ }^{3}\right)$.

It is well established that 2 (ax)-hydroxygibbane $1 \rightarrow 4$ a-lactones are epimerized in dilute aqueous alkali to the more stable $2(\mathrm{eq})$ hydroxy-compounds $\left.{ }^{2,3}\right)$. Thus gibberellin C (Ia) gives the 2 (eq)-hydroxy-epimer ${ }^{2}$ ) (IIa, isogibberellin $A_{1}{ }^{3}$ by treatment with dilute alkali. A gibb-4a (4b)-ene diester (IIIa), derived from the 2 (eq) -hydroxy-epimer (IIa) is now converted to gibberellin C. This constitutes a part of the efforts directed toward the total synthesis of gibberellin $\mathrm{C}$.

2 (eq) -Hydroxy keto ester (IIb) afforded oily 2 (eq)-hydroxy keto diester (IIIa) when

\footnotetext{
* Part XI, K. Mori, M. Matsui and Y. Sumbi, This Journal, 28, 72 (1964).

1) K. Mori, M. Matsui and Y. Sumiki, This Journal, 27, 530 (1963). 2498. B.E. Cross, J.F. Grove and A. Morisson, J. Chem. Soc., 1961.

3) N. Takahashi, Y. Seta, H. Kitamura, A. Kawarada and Y. Sumiki, This Journal, 23, 493 (1959).
}

gibberellin $A_{1}$ methyl ester, the existence of The infrared spectrum of the corresponding 2 (eq) -acetate (IIIb), m.p. $137 \sim 138^{\circ} \mathrm{C}$, was clearly different from that of the known $2(\mathrm{ax})$-acetate $\left.(\mathrm{Vb})^{4}\right)$. The assigned structure (IIIa) was supported by the fact that the oily 2 (eq) -hydroxy ester, upon oxidation, gave a crystalline diketo ester which was identical with the known diketo ester (IV) derived from 2 (ax)-hydroxy diester (Va). Treatment of 2 (eq)-hydroxy diester (IIIa) with aqueous sulfuric acid followed by ethereal diazomethane afforded the expected relactonized product, the 2 (eq) -hydroxy keto ester (IIb).

The next problem was the conversion of the 2 (eq)-hydroxy keto ester (IIb) to gibberellin $\mathrm{C}$ methyl ester (Ib). In case of gibberellin $A_{1}$ methyl ester, the existence of an equilibrium between the 2-hydroxy-epimers has already been shown by the British workers $^{2}$. The same situation was expected to exist in case of gibberellin $\mathrm{C}$ methyl ester, too. Actually about $10 \%$ of gibberellin $\mathrm{C}$

\footnotetext{
4) D.C. Aldridge, J.F. Grove, R.N. Speake, B.K. Tidd and W. Klyne, J. Chem. Soc, $1963,143$.

5) B.E. Cross, ibid., 1960, 3022.
} 

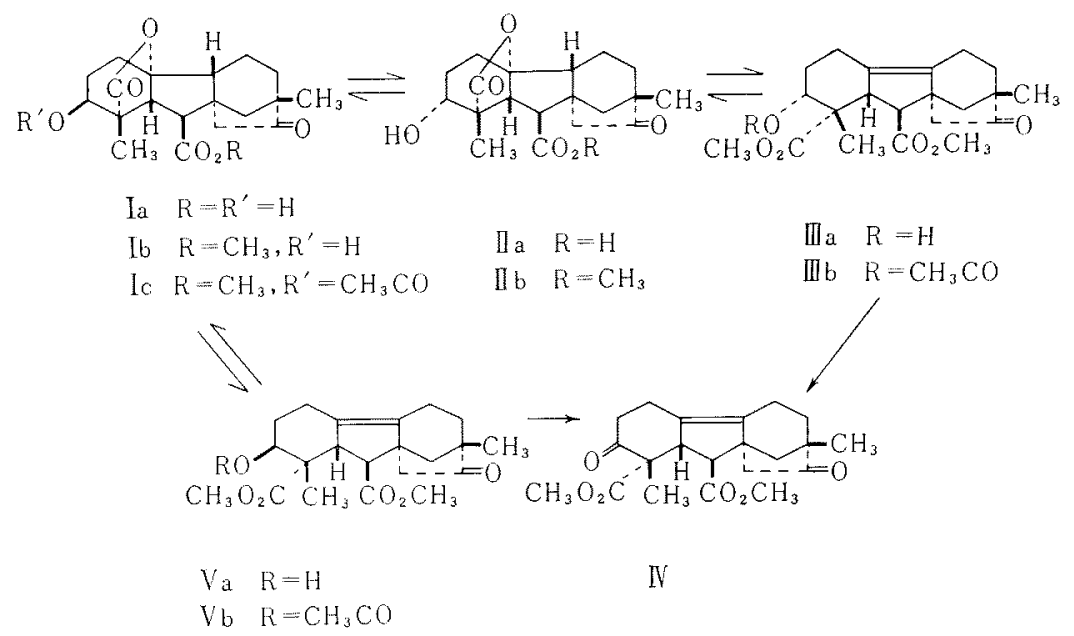

methyl ester (Ib) was isolated when the 2 (eq) -hydroxy-epimer (IIb) was shaken with $0.01 \mathrm{~N}$-sodium hydroxide. Treatment of the former with dilute hydrochloric acid gave gibberellin C (Ia). This concluded the conversion of 2 (eq)-hydroxy diester (IIIa) to gibberellin $\mathrm{C}$ (Ia) .

Desoxogibberellin C. In connection with other synthetic studies, gibberellin $\mathrm{C}$ derivatives were prepared in which C-8 keto group was reduced to methylene.

Both gibberellin C methyl ester (Ib) and its acetate (Ic) gave the corresponding thio- ketals (VIa, m.p. $222 \sim 223^{\circ} \mathrm{C}$, and VIb, oil) when treated with ethanedithiol and boron trifluoride etherate. Desulfurization of these compounds with Raney nickel W-7 in dioxane afforded desoxogibberellin $\mathrm{C}$ methyl ester (VIIb), m.p. $159 \sim 160^{\circ} \mathrm{C}$, and its acetate (VIIc), m.p. $134 \sim 135^{\circ} \mathrm{C}$. The acetate (VIIc) was also obtained by acetylation of the hydroxy ester (VIIb). Chromic acid oxidation of the hydroxy ester (VIIb) gave a keto ester (VIII), m.p. $132 \sim 133^{\circ} \mathrm{C}$. The hydroxy ester (VIIb) was hydrolyzed with difficulty by dilute hydrochloric acid to afford impure

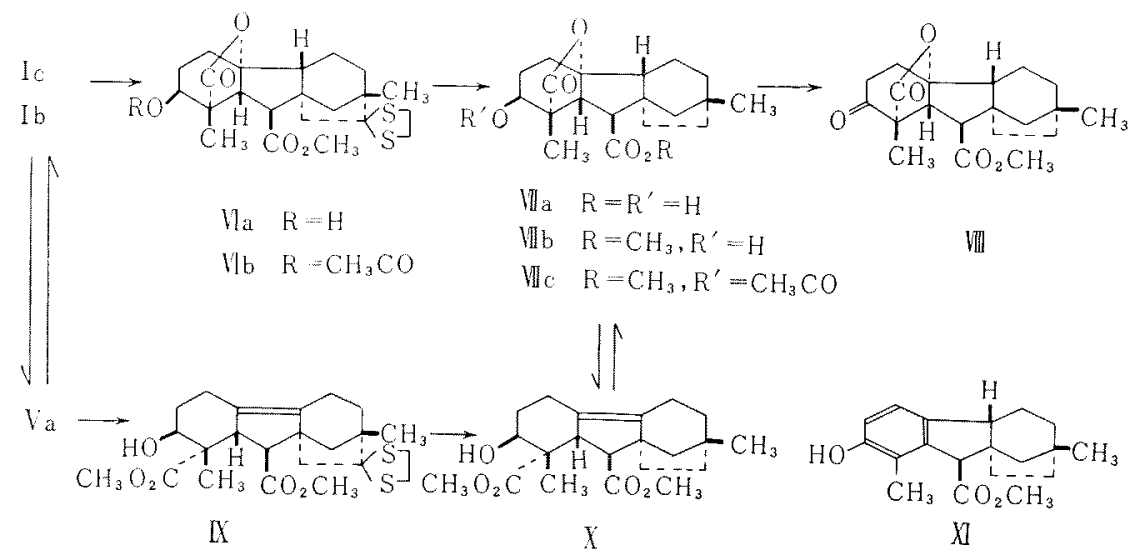


desoxogibberellin C (VIIa), m.p. $205 \sim 210^{\circ} \mathrm{C}$, in poor yield.

The oily thioketal (IX) of 2 (ax)-hydroxy diester (Va) was desulfurized to give a desoxo diester (X), m.p. $136 \sim 137^{\circ} \mathrm{C}$. This was shown to be identical with the methanolysis product of desoxogibberellin C methyl ester (VIIb). Relactonization of this diester (X) with hot aqueous sulfuric acid afforded a very small amount of the expected lactone as its methyl ester (VIIb). Desoxo compounds so far examined, including synthetic materials such as the ester $(\mathrm{XI})^{6}$, were all acid-labile, suggesting their tendency to undergo skeletal rearrangements with acid.

\section{EXPERIMENTAL}

All melting points were not corrected. Infrared spectra were measured as Nujol mulls unless otherwise stated.

Methanolysis of the 2(eq)-Hydroxy Keto Ester (IIb). A solution of the ester (IIb, $600 \mathrm{mg}$ ) in dry methanol $(30 \mathrm{ml})$ saturated with hydrogen chloride was heated under reflux for 4 hrs in a slow stream of hydrogen chloride. The solution was poured on ice and extracted with ethyl acetate. To the extract was added ethereal diazomethane. The solution was washed with water and dried over sodium sulfate. Recovery gave a gum which was chromatographed on alumina $(15 \times 2.5 \mathrm{~cm})$ in benzene. Elution with benzene-ether (1:1, $500 \mathrm{ml}$ ) afforded a small amount of intractable gum (about $50 \mathrm{mg}$, Beilstein test positive). Ether (1 l) eluted nothing. Elution with benzene-methanol (150:1, $150 \mathrm{ml}$ after $350 \mathrm{ml}$ of forerun) gave the oily diester, methyl 1,7-dimethyl-2a-hydroxy-8-oxo-7a-gibb4a (4b) -ene-1,10-dicarboxylate (IIIa, about $300 \mathrm{mg}$ ) . All attempts to crystallize this failed. The oil shows different infrared spectrum from that of the 2 (ax)hydroxy-epimer. $\nu_{\max }$ (liquid film) 3520, 1785, 1720 $\mathrm{cm}^{-1} \quad$ Acetate (IIIb). The oily diester (IIIa) was acetylated with acetic anhydride and pyridine. Elongated prisms from ether-petroleum ether, m.p. 137 $138^{\circ} \mathrm{C}$. Anal. Found: C, 66.05; H, 6.92. Calcd. for $\mathrm{C}_{23} \mathrm{H}_{30} \mathrm{O}_{7}: \mathrm{C}, 66.01 ; \mathrm{H}, 7.29 \%$. $\nu_{\max } 1798,1718 \mathrm{~cm}^{-1}$. Further elution with benzene-methanol (150:1, $250 \mathrm{ml})$ gave a small amount of gum. Then elution with

6) K. Mori, T. Ogawa, M. Matsui and Y. Sumiki, unpublished. benzene-methanol (150:1, 100 $\mathrm{ml}$ and 50:1, $300 \mathrm{ml})$ afforded the starting material (IIb, $100 \mathrm{mg}$ ).

Oxidation of the 2(eq)-Hydroxy Diester (IIIa) to the Diketo Diester (IV). To a solution of the hydroxy diester (IIIa, $30 \mathrm{mg}$ ) in acetone $(1 \mathrm{ml}$ ) was added Jones' chromic acid reagent ${ }^{-1}(0.05 \mathrm{ml})$ at $0^{\circ} \mathrm{C}$ and the mixture was left to stand at room temperature for 1.5 hrs. Then the mixture was diluted with water and extracted with ether. Removal of ether followed by trituration of the residue with methanol afforded needles of methyl 1,7-dimethyl-2,8-dioxo-7 $a^{-}$ gibb-4a (4b) -ene-1,10-dicarboxylate (IV). Needles from ethyl acetate-petroleum ether, m.p. $116 \sim 118^{\circ} \mathrm{C} . \nu_{\max }$ $1730,1715,1220,1070 \mathrm{~cm}^{-1}$. Mixed m.p. with the diketo diester prepared from 2 (ax)-epimer (Va) showed no depression. The infrared spectrum was identical with that of the ester derived from 2 (ax) epimer (Va).

Relactonization of the 2(eq)-Hydroxy Diester (IIIa) to the 2(eq)-Hydroxy-Epimer (IIb) of Gibberellin $\mathrm{C}$ Methyl Ester. A mixture of the diester (IIIa, about $190 \mathrm{mg}$ ), methanol (2 $\mathrm{ml})$, water $(10 \mathrm{ml})$ and concd. sulfuric acid $(3 \mathrm{ml})$ was refluxed for $4.5 \mathrm{hrs}$. After cooling, the mixture was extracted with ethyl acetate. The cxtract was washed with water, treated with ethereal cliazomethane, dried and evaporated. The residue crystallized from ethyl acetate-petroleum ether to give needles of the desired lactone (IIb), m.p. $222 \sim 225^{\circ} \mathrm{C}$. Yicld, $80 \mathrm{mg} . \quad \nu_{\max } 3560,1756,1730$ $\mathrm{cm}^{-1}$ This was identified with an authentic sample of the 2 (eq)-hydroxy-epimer (IIb) by mixed m.p. and infrared measurement. The starting diester (IIA) was recovered from the mothcr liquor.

Conversion of the 2(eq)-Hydroxy-Epimer (IIb) to Gibberellin $C$ Methyl Ester (Ib). The 2(eq)-hydroxy keto ester (IIb, $250 \mathrm{mg}$ ) was shaken with $0.01 \mathrm{~N}$ sodium hydroxide $(150 \mathrm{ml})$ for 2 hrs at room temperature. Dissolution was complete in $15 \mathrm{~min}$. The acidified solution was extracted with ethyl acetate. The extract was washed with aqueous sodium bicarbonate, dried and evaporated. The residue in ethyl acetate $(5 \mathrm{ml})$ was chromatographed on alumina $(18 \times 2 \mathrm{~cm})$ in benzene. Fractional elution with benzene-methanol (200:1) gave, after $300 \mathrm{ml}$ of forerun, gibberellin $\mathrm{C}$ methyl ester ( $\mathrm{lb}$, about $13 \mathrm{mg}$ in $150 \mathrm{ml}$ of eluate), m.p. $220 \sim 223^{\circ} \mathrm{C}$, identified by mixed m.p. determination and infrared measurement.

7) A. Bowers, T.G. Halsall, E.R.H. Jones and A.J. Lemin, J. Chem. Soc., 1953, 2548 . 
Further elution $(500 \mathrm{ml})$ afforded the starting $2(\mathrm{eq})$ hydroxy-epimer (IIb, about $150 \mathrm{mg}$ ).

Gibberellin C (Ia) from its Methyl Ester (Ib) by Acid Hydrolysis. Gibberellin C methyl ester (Ib, $50 \mathrm{mg}$ ) in methanol $(2 \mathrm{ml})$ was refluxed with dilute hydrochloric acid $(1: 4,10 \mathrm{ml})$ for 3.5 hrs. The mixture was extracted with ethyl acetate. The extract was dried over sodium sulfate and concentrated. Crystallization of the residure from ethyl acetate-petroleum ether afforded prisms $(25 \mathrm{mg})$ of gibberellin $\mathrm{C}(\mathbf{I a})$, m.p. $233-237^{\circ} \mathrm{C}$. Recrystallization raised the m.p. to $248 \sim 250^{\circ} \mathrm{C}$. $v_{\max } 3520,3470,3330,1758,1718,1700$, $1640 \mathrm{~cm}^{-1}$ This was identified by mixed m.p. determination and infrared measurement.

Gibberellin C Methyl Ester 8-Dithioethyleneketal (VIa). Gibberellin C methyl ester ( $\mathrm{Ib}, 4.5 \mathrm{~g}$ ) in chloroform $(80 \mathrm{ml})$ was treated with ethanedithiol $(4.5 \mathrm{ml})$ and boron trifuoride etherate $(4.5 \mathrm{ml})$. After having been left to stand overnight at room temperature, the mixture was poured into ice-water. The chloroform layer was separated, washed with brine, dried and evaporated. The residue crystallized when triturated with ether. Yield, $4.7 \mathrm{~g} \quad(87 \%)$. Needles from ethyl acetate-petroleum ether, m.p. $222 \sim 223^{\circ} \mathrm{C}$. Anal. Found: $\mathrm{C}, 59.94 ; \mathrm{H}, 6.81$. Calcd. for $\mathrm{C}_{22} \mathrm{H}_{30} \mathrm{O}_{5} \mathrm{~S}_{2}$ : C, $60.24 ; \mathrm{H}, 6.67 \%, \nu_{\max } 3484,1752,1732 \mathrm{~cm}^{-1}$.

Desoxogibberellin C Methyl Ester (VIIb). The above described thioketal (VIa, $4.6 \mathrm{~g})$ in dioxane $(200$ ml) was boiled with Raney nickel $W-7$ (35 g) for 12 hrs. The catalyst was filtered off and washed with dioxane. The combined filtrate and washings were concentrated in vacuo. Trituration of the residue with petroleum ether afforded $2.7 \mathrm{~g}(75 \%)$ of crystals. Prisms from ethyl acetate-petroleum ether, m.p. 159 $160^{\circ} \mathrm{C}$. Anal. Found: C, 69.25; H, 7.93. Calcd. for $\mathrm{C}_{30} \mathrm{H}_{\mathrm{m}} \mathrm{O}_{5}: \mathrm{C}, 68.94 ; \mathrm{H}, 8.10 \%$. $\nu_{\max } 3540,1758$, $1728 \mathrm{~cm}^{-1}$

Acetate (VIIc) of Desoxogibberellin C Methyl Ester. (A) The above described ester (VIIb, $80 \mathrm{mg}$ ) in pyridine $(1 \mathrm{ml})$ was acetylated with acetic anhydride $(1 \mathrm{ml})$. Subsequent treatments afforded $80 \mathrm{mg} \mathrm{(90 \% )}$ of crystals. Needles from ethyl acetate-petroleum ether, m.p. $134 \sim 135^{\circ} \mathrm{C}$. Anal. Found: C, 68.04; H, 7.69. Calcel for $\mathrm{C}_{22} \mathrm{H}_{30} \mathrm{O}_{43}: \mathrm{C}, 67.67 ; \mathrm{H}, 7.74 \%$. $\nu_{\max }$ $1765,1738,1722 \mathrm{~cm}^{-1}$ (B) Gibberellin $C$ methyl ester acetate (Ic, $900 \mathrm{mg}$ ) in chloroform $(15 \mathrm{ml})$ was treated with boron trifluoride etherate $(1 \mathrm{ml})$ and ethanedithiol ( $1 \mathrm{ml})$. Subsequent treatments as in the preparation of the thioketal (VIa) afforded an oil. This oil in benzene-petroleum ether $(1: 1,10 \mathrm{ml})$ was chromatographed on alumina $(20 \times 1.8 \mathrm{~cm})$ in benzene-petroleum ether $(1: 1)$. The column was washed with benzene-petrolcum ether $(1: 1,500 \mathrm{ml})$ to remove ethanedithiol. Elution with benzenemethanol (150:1,400 ml) gave the desired thioketal (VIb) as an oil. This was boiled with Raney nickel $\mathrm{W}-7$ (15 g) in dioxane $(100 \mathrm{ml})$ for $13 \mathrm{hrs}$. Subsequent treatments as described before afforded 700 mg $(87 \%)$ of needles, which was identical (mixed m.p. and infrared spectrum) with the acetate obtained by acetylation as described above.

Oxidation of Desoxogibberellin C Methyl Ester (VIIb). To a solution of desoxogibberellin $\mathrm{C}$ methyl ester (VIIb, $800 \mathrm{mg}$ ) in acetone $(15 \mathrm{ml})$ was added $0.6 \mathrm{ml}$ of Jones' reagent at $5^{\circ} \mathrm{C}$. The mixture was allowed to stand at room temperature for an hour and then diluted with water $(30 \mathrm{ml})$. Precipitated crystals of methyl 1-carboxy-1,7-dimethyl-2-oxo-4a-hydroxy-7a. gibbane-10-carboxylate $1 \rightarrow 4$ a-lactone (VIII) were col. lected. Yield, $750 \mathrm{mg}(94 \%)$. Needles from ethyl acetate-petroleum ether, m.p. $132 \sim 133^{\circ} \mathrm{C}$. Anal. Found: $\mathrm{C}, 69.57 ; \mathrm{H}, 7.19$. Calcd. for $\mathrm{C}_{29} \mathrm{H}_{\because 4} \mathrm{O}_{5} ; \mathrm{C}$, $69.34 ; \mathrm{H}, 7.57 \%$. $\nu_{\max } 1770,1732,1714 \mathrm{~cm}^{-1}$.

Desoxogibberellin C (VIIa). Desoxogibberellin C methyl ester (VIIb, $500 \mathrm{mg}$ ) was boiled with dilute hydrochloric acid $(1: 5,30 \mathrm{ml})$ for $4 \mathrm{hrs}$. The mixture was extracted with ethyl acetate. The extract was separated into neutral (250 $\mathrm{mg}$ ) and acidic (150 mg) fractions by extraction with sodium bicarbonate and recovery. The crystalline neutral fraction was the recovered starting material. The acidic fraction in ethyl acetate $(3 \mathrm{ml})$ was chromatographed on silicic acid $(14 \times 1 \mathrm{~cm})$. Elution with chloroform-ethyl acetate (4:1) afforded $5 \mathrm{mg}$ of crystals. Prisms from ethyl acetate-petroleum ether, m.p. $205 \sim 210^{\circ} \mathrm{C}$ (dec.). Anal. Found: C, 70.48; H, 7.75. (1.016 mg Subst.; $\mathrm{CO}_{2}$, $\left.2.624 \mathrm{mg} ; \mathrm{H}_{2} \mathrm{O}, 0.704 \mathrm{mg}\right)$. Calcd. for $\mathrm{C}_{10} \mathrm{H}_{28} \mathrm{O}_{5}: \mathrm{C}$, $68.24 ; \mathrm{H}, 7.84 \%$. $\nu_{\max } 3490,1750,1728 \mathrm{~cm}^{-3}$

Methyl 1,7-Dimethyl-2 $\beta$-hydroxy-7 $\alpha$-gibb-4a (4b)-ene1,10-dicarboxylate $(X)$. The hydroxy keto diester $\mathrm{Va}$, $2.0 \mathrm{~g}$ ) in chloroform $(30 \mathrm{ml})$ was treated with ethanedithiol $(2 \mathrm{ml})$ and boron trifluoride etherate $(2 \mathrm{ml})$. Subsequent treatments including chromatography on alumina as described in the preparation of the thioketal (VIb) afforded the oily thioketal (IX). This was desulfurized by boiling with Raney nickel W-7 $(15 \mathrm{~g})$ in dioxane $(150 \mathrm{ml})$. Subsequent treatments 
as usual gave $0.75 \mathrm{~g} \mathrm{(39 \% )} \mathrm{of} \mathrm{crystals} \mathrm{(X).} \mathrm{Prisms}$ from ethyl acetate-petroleum ether, m.p. $136 \sim 137^{\circ} \mathrm{C}$. Anal. Found: $\mathrm{C}, 69.80 ; \mathrm{H}, 8.20$. Calcd. for $\mathrm{C}_{31} \mathrm{H}_{30} \mathrm{O}_{5}$ : C, $69.58 ; \mathrm{H}, 8.34 \%$. $\nu_{\max } 3508,1730,1708 \mathrm{~cm}^{-1}$

Methanolysis of Desoxogibberellin C Methyl Ester (VIIb). A solution of the ester (VIIb, $600 \mathrm{mg}$ ) in methanol $(30 \mathrm{ml})$ was treated with dry hydrogen chloride as described in the preparation of the diester (IIIa). The product in a small amount of ethyl acetate was chromatographed on alumina $(10 \times 1.5 \mathrm{~cm})$ in benzene. Fractional elution with benzene-methanol $(200: 1)$ gave methyl 1,7-dimethyl$2 \beta$-hydroxy-7a-gibb-4a (4b)-ene-1,10-dicarboxylate (X, $150 \mathrm{mg}$ ), identified by mixed m.p. determination and infrared measurement. Further elution recovered a small amount of the starting material (VIIb, $20 \mathrm{mg}$ ).
Relactonization of the Desoxo Diester $(X)$ to Desoxogibberellin C Methyl Ester (VIIb). A mixture of the desoxo ester (X, $100 \mathrm{mg})$, acetic acid $(8 \mathrm{ml})$, water $(9 \mathrm{ml})$ and concd. sulfuric acid $(3 \mathrm{ml})$ was refluxed for 5 hrs. The mixture was extracted with ethyl acetate and the extract washed with water, dried, treated with dried ethereal diazomethane and evaporated. The product was chromatographed on alumina $(8 \times 1 \mathrm{~cm})$ in benzene. Elution with benzene-methanol (200:1) gave about $30 \mathrm{mg}$ of intractable gum and then about $10 \mathrm{mg}$ of lactonic fraction (infrared measurement). About $3 \mathrm{mg}$ of crystals were obtained, of which infrared spectrum was identical with that of desoxogibbercllin C methyl ester (VIIb).

Acknowledgement. Our sincere thanks are due to Kyowa Fermentation Industry Co. for the gift of gibberellic acid used in this work. 